\title{
Rotational Spectra of Fluorodiacetylene and Fluorotriacetylene Produced by Electrical Discharge
}

\author{
Helmut Dreizler ${ }^{a}$, Santiago Mata, Alberto Lesarri, Juan C. López, Susana Blanco, \\ and José L. Alonso \\ Departamento de Química-Física, Facultad de Ciencias, Universidad de Valladolid, \\ 47005 Valladolid, Spain \\ ${ }^{a}$ Institut für Physikalische Chemie der Christian-Albrechts-Universiät Kiel, \\ Olshausenstr. 40, D-24098 Kiel \\ Reprint requests to Prof. H. D.; Fax: +49(0)431 880 1416; E-mail: dreizler@phc.uni-kiel.de
}

Z. Naturforsch. 57 a, 76-78 (2002); received December 4, 2001

The rotational spectra of discharge produced ${ }^{13} \mathrm{C}$ isotopomers of fluorodiacetylene were recorded with high sensitivity to improve the centrifugal distortion analysis. Stimulated by the sensitivity attained by the spectrometer the investigation was extended to detect the hitherto unknown fluorotriacetylene. The spectrum of a linear molecule was found, which with high probability belongs to fluorotriacetylene.

Key words: Rotational Spectra; Fluoropolyacetylenes; Discharges; Molecular Beam; Fourier Transform Spectroscopy.

\section{Introduction}

In the recent years the rotational spectra of many molecules, which were produced by an electrical discharge in a pulsed beam nozzle, were investigated by molecular beam Fourier transform microwave (MB FTMW) spectroscopy [1]. After the initial experiments of Grabow, Heineking, and Stahl [2] this field was subsequently investigated by several groups with great success: Gerry et al. [3, 4], Endo et al. [5], Thaddeus et al. [6]. In Kiel, Sutter and Dreizler contributed to the field by two publications [7, 8]. In this paper we report an extension of this work.

It was possible to study many new molecular species, which were otherwise difficult to synthesize. Many of them were observed in the interstellar space [6]. Further deuteration was possible, and reaction paths in the discharge were proposed $[7,8]$.

\section{Experimental}

Following these lines the MB FTMW spectrometer [9] in Valladolid was equipped with a discharge nozzle similar to that given in Fig. 1 of [8] or that described in the appendix B of [6]. The discharge tube is of $3 \mathrm{~mm}$ diameter and $16 \mathrm{~mm}$ length, the ring electrodes have a distance of $4 \mathrm{~mm}$. The downstream following reaction tube is of $4.5 \mathrm{~mm}$ diameter and $16 \mathrm{~mm}$ length. A positive upstream electrode proved to result in higher sensitivity. The downstream electrode was on ground. Further, the parts 28 to 33 of Fig. 1 of [7] (HV power supply, HV switch, pulse generator, limiting resistor, HV probe, oscilloscope) were incorporated into the spectrometer.

To test the set up with discharge produced fluorodiacetylene, $\mathrm{F}(\mathrm{C} \equiv \mathrm{C})_{2} \mathrm{H}$, [8], a sample prepared with neon as carrier gas and approximately $1 \%$ of 1,1 difluoroethene, $\mathrm{CF}_{2} \mathrm{CH}_{2}$, as precursor gas (Aldrich Chemical $\mathrm{Co}$ ) was used. Backing pressures up to 5 bar and discharge voltages between 800 to $1400 \mathrm{~V}$ were applied. With a valve opening time of 0.8 to $1 \mathrm{~ms}$ the high voltage was on for $0.75 \mathrm{~ms}$ with a delay of $0.25 \mathrm{~ms}$ relative to the starting of the gas pulse. We were able to measure the $J=2-1$ and $3-2$ transitions of all four ${ }^{13} \mathrm{C}$ isotopomers in natural abundance of $1 \%$. About 8192 experiment cycles were necessary. The results are given in Table 1. The measurements were used to improve the centrifugal distortion analysis with the Hamiltonian

$$
H=B J(J+1)+D_{J} J^{2}(J+1)^{2} .
$$

Using the program of Pickett [10] and including the high $J$ transitions given in $[11,12]$ results in the 
Table 1. Low $J$ rotational transitions of ${ }^{13} \mathrm{C}$-isotopomers of fluorodiacetylene, FCCCCH [MHz]. Estimated experimental uncertainty $2 \mathrm{kHz}$.

\begin{tabular}{lccr}
\hline Isotopomer & $J=2-1$ & $J=3-2$ & Ref. \\
\hline $\mathrm{F}^{13} \mathrm{CCCCH}$ & 8116.7033 & 12175.0500 & \\
$\mathrm{FC}^{13} \mathrm{CCCH}$ & 8151.4269 & 12227.1354 & \\
$\mathrm{FCC}^{13} \mathrm{CCH}$ & 8077.5380 & 12116.2989 & \\
$\mathrm{FCCC}^{13} \mathrm{CH}$ & 7916.7035 & 11875.0506 & \\
$\mathrm{FCCCCH}$ & 8152.3905 & 12228.5810 & {$[8]$} \\
\hline
\end{tabular}

Table 2. Rotational $[\mathrm{MHz}]$ and centrifugal distortion $[\mathrm{kHz}]$ constants of fluorodiacetylene and fluorotriacetylene. Higher order centrifugal distortion terms are not determinable.

\begin{tabular}{lclr}
\hline & $B$ & \multicolumn{1}{c}{$D_{J}$} & Ref. \\
\hline FCCCCH & $2038.09840(14)$ & $0.08459(18)$ & {$[8]$} \\
$\mathrm{F}^{13} \mathrm{CCCCH}$ & $2029.17650(28)$ & $0.083252(606)$ & \\
$\mathrm{FC}^{13} \mathrm{CCCH}$ & $2037.85741(28)$ & $0.084207(535)$ & \\
$\mathrm{FCC}^{13} \mathrm{CCH}$ & $2019.38480(28)$ & $0.083069(606)$ & \\
$\mathrm{FCCC}^{13} \mathrm{CH}$ & $1979.17652(28)$ & $0.079141(513)$ & \\
$\mathrm{F}(\mathrm{C} \equiv \mathrm{C})_{3} \mathrm{H}$ & $755.74895(33)$ & $0.00807(195)$ & \\
\hline
\end{tabular}

rotational and centrifugal distortion constants given in Table 2.

The results for the main isotopomer $\mathrm{F}(\mathrm{C} \equiv \mathrm{C})_{2} \mathrm{H}$, [8] have been included in Table 2. By adding the low $J$ lines, the results gain in precision compared to [12].

Stimulated by the results and experience given in $[6]$ that by adding another $(\mathrm{C} \equiv \mathrm{C})$-group the intensity of the lines of the extended species reduces to 10 to $20 \%$, and by the sensitivity demonstrated above by the ${ }^{13} \mathrm{C}$ isotopomers we searched for the hitherto unknown fluorotriacetylene, $\mathrm{F}(\mathrm{C} \equiv \mathrm{C})_{3} \mathrm{H}$.

For prediction we transferred the structural data from $\mathrm{F}(\mathrm{C} \equiv \mathrm{C})_{2} \mathrm{H}[12]$ and $\mathrm{HC} \equiv \mathrm{CH}[13]$ in the following way:

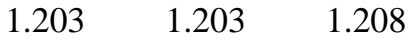

$$
\begin{aligned}
& \mathrm{F}-\mathrm{C} \equiv \mathrm{C}-\mathrm{C} \equiv \mathrm{C}-\mathrm{C} \equiv \mathrm{C}-\mathrm{H} \\
& \begin{array}{llll}
1.273 & 1.371 & 1.371 & 1.056
\end{array}
\end{aligned}
$$

Bond lengths in $\AA$.

A moment of inertia of $I=668.6$ amu $\AA^{2}$ resulted. The predicted rotational constant was $B=755.8 \mathrm{MHz}$.

$\mathrm{Ab}$ initio calculations were additionally performed using GAUSSIAN 98 [14] programs in order to predict the rotational constants of $\mathrm{F}(\mathrm{C} \equiv \mathrm{C})_{3} \mathrm{H}$. First we tested the reliability of these calculations on the $\mathrm{F}(\mathrm{C} \equiv \mathrm{C})_{2} \mathrm{H}$ molecule. We initially compared the rotational constants calculated using 6-31G(d,p) and 6$311+\mathrm{G}(\mathrm{d}, \mathrm{p})$ basis sets in combination with MP2 and
Table 3. Rotational transitions of fluorotriacetylene, $\mathrm{F}(\mathrm{C} \equiv \mathrm{C})_{3} \mathrm{H}$. Estimated experimental uncertainty $2 \mathrm{kHz}$.

\begin{tabular}{ccccc}
\hline$J^{\prime}$ & - & $J$ & $\nu_{\exp }[\mathrm{MHz}]$ & $\nu_{\exp }-\nu_{\text {calc }}[\mathrm{kHz}]$ \\
\hline 5 & - & 4 & 7557.48650 & 1.08 \\
6 & - & 5 & 9068.97990 & -0.48 \\
7 & - & 6 & 10580.47390 & -0.27 \\
8 & - & 7 & 12091.96660 & -0.01 \\
9 & - & 8 & 13603.45780 & 0.3 \\
10 & - & 9 & 15114.94470 & -1.95 \\
11 & - & 10 & 16626.43440 & 0.54 \\
12 & - & 11 & 18137.91970 & 0.7 \\
\hline
\end{tabular}

B3LYP methods with the corresponding experimental value given in [12]. The MP2 calculation gave bond distances larger than those reported, and this resulted in values of $B$ smaller than the experimental value. The density functional B3LYP hybrid method predicts a rotational constant in better agreement with the experimental observation and finally we decided to use a B3LYP/6-311+G(d,p) level of theory to obtain the quantum chemical value $B_{\mathrm{QC}}$ for $\mathrm{F}(\mathrm{C} \equiv \mathrm{C})_{3} \mathrm{H}$. The predicted value $B_{\mathrm{QC}} \mathrm{MHz}$ was scaled with the ratio $B_{\mathrm{OBS}}\left(\mathrm{F}(\mathrm{C} \equiv \mathrm{C})_{2} \mathrm{H}\right) / B_{\mathrm{QC}}\left(\mathrm{F}(\mathrm{C} \equiv \mathrm{C})_{2} \mathrm{H}\right)$ to give the final prediction $B_{\mathrm{SC}}=756.3 \mathrm{MHz}$.

An extended search by scans [15] in the region of the $J=8-7$ resulted in a weak signal. Improving with higher backing pressures up to 7 bar and higher voltages to $1400 \mathrm{~V}$ resulted in the frequencies given in Table 3. Figure 1 gives an example. The results of a centrifugal distortion analysis have been included in Table 2. It may be noted that the rotational constant $B=755.74895$ (33) $\mathrm{MHz}$ is very close to the predicted one and that the centrifugal distortion constant $D_{\mathrm{J}}$ is about one order of magnitude smaller for $\mathrm{F}(\mathrm{C} \equiv \mathrm{C})_{3} \mathrm{H}$ than for $\mathrm{F}(\mathrm{C} \equiv \mathrm{C})_{2} \mathrm{H}$, indicating a slower rotation.

\section{Discussion}

The agreement between experiment and prediction is a strong indication that the spectrum of the linear molecule is really that of fluorotriacetylene, $\mathrm{F}(\mathrm{C} \equiv \mathrm{C})_{3} \mathrm{H}$. Also the reduction of the centrifugal distortion constant supports this conclusion. It must be a dipolar molecule composed only of hydrogen, carbon and fluorine, as the precursor only provides these atoms.

Comparing the normalized $\left(\frac{S}{N}\right)_{\text {norm }}=\frac{S}{N} n_{\mathrm{c}}^{-1 / 2}$ [8] signal to noise ratio with $n_{\mathrm{c}}$, the number of cycles as a rough measure of the intensity of the signals we estimated a decrease of the signals, from $\mathrm{F}(\mathrm{C} \equiv \mathrm{C})_{2} \mathrm{H}$ to $\mathrm{F}(\mathrm{C} \equiv \mathrm{C})_{3} \mathrm{H}$ by a factor of $26(6)$. This rough method 


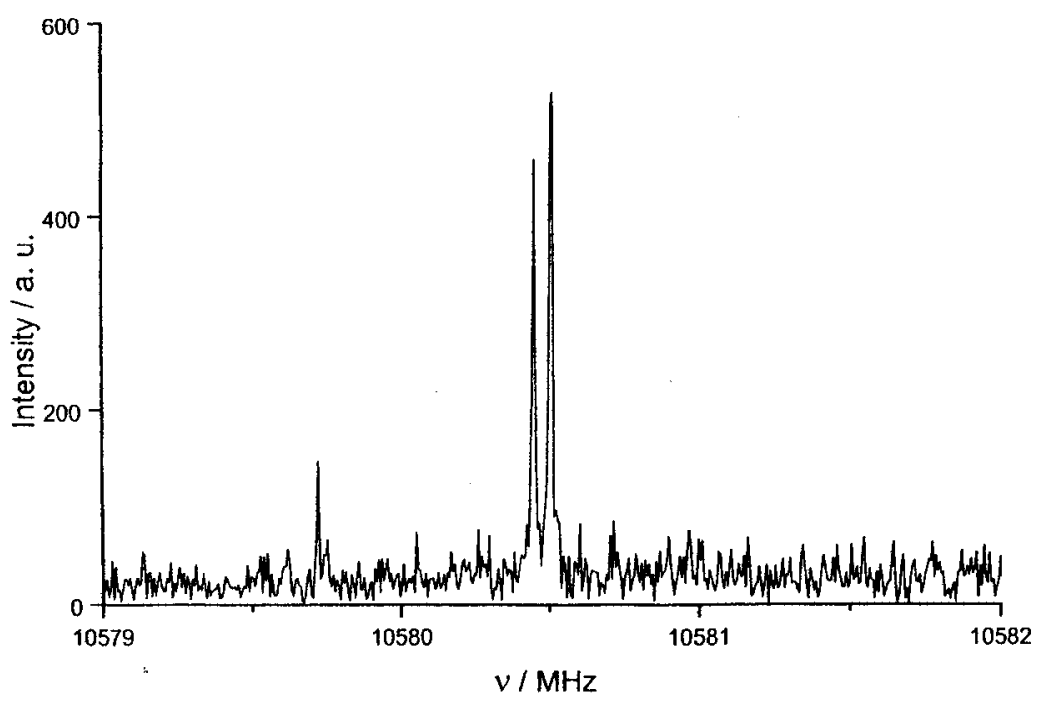

Fig. 1. A section of $3 \mathrm{MHz}$ of the amplitude spectrum of fluorotriacetylene, $\mathrm{F}(\mathrm{C} \equiv \mathrm{C})_{3} \mathrm{H}$, showing the Doppler doublet of the $J=7-6$ transition. $4 \mathrm{k}$ data points in the time domain with 40 ns interval, polarizing frequency $10580.47 \mathrm{MHz}, 1024$ averaging cycles, $+1400 \mathrm{~V}$ discharge voltage. This recording results from an optimal adjustment of all parameters. The line width (HWHH) is about $6 \mathrm{kHz}$. A coherent perturbation is visible at lower frequencies. was checked for $\mathrm{F}(\mathrm{C} \equiv \mathrm{C})_{2} \mathrm{H}$ and its ${ }^{13} \mathrm{C}$-species. It resulted a factor of $143(35)$. This value is not far from 99, which results from the natural abundance of ${ }^{13} \mathrm{C}$.

Presently it seems not possible for reasons of sensitivity to find the ${ }^{13} \mathrm{C}$ isotopomers in natural abundance, which would prove definitely that $\mathrm{F}(\mathrm{C} \equiv \mathrm{C})_{3} \mathrm{H}$ is the obscrved molecule.

It is interesting to mention that the hexatriynyl radical, $\mathrm{C}_{6} \mathrm{H}$, has been observed in the interstellar space [16] and in the laboratory [17].

[1] H. Dreizler, Ber. Bunsenges. Phys. Chem. 99, 1451-1461 (1995).

[2] J.-U. Grabow, N. Heineking, and W. Stahl, Z. Naturforsch. 46a, 914-916 (1991).

[3] C. Styger and M. C. L. Gerry, Chem. Phys. Lett. 188, 213-216 (1992).

[4] C. Styger and M. C. L. Gerry, J. Mol. Spectrosc. 158, 328338 1993).

[5] Y.Endo, H. Konguchi, and Y. Oshima, Faraday Discuss. 97, 341-360 (1994) and subsequent publications.

[6] M.C. McCarthy, W.Chen, M. J. Travers, and P. Thaddeus, Astrophys. J. Suppl. Series 129, 611-623 (2000) and citations herein.

[7] D. H. Sutter and H. Dreizler, Z. Naturforsch. 55a, 695-705 (2000).

[8] D. H. Sutter and H. Dreizler, Z. Naturforsch. 56a, 425-438 (2001).

[9] J. L. Alonso, F. J. Lorenzo, J. C. Lopez, A. Lesarri, S. Mata, and H. Dreizler, Chem. Phys. 218, 267-275 (1997).

[10] H. M. Pickett, J. Mol. Spectrosc. 148, 371-377 (1991).

[11] T. Okabayashi, K. Tanaka, and T. Tanaka, J. Mol. Spectrosc. 137, 9-12 (1989).

[12] L.Dore, L. Cludi, A. Mazzavillani, G. Cazzoli, and C. Puzzarini, Phys. Chem. Chem. Phys. 1, 2275-2278 (1999).

[13] R. J. Berry and M. D. Harmony, Struct. Chem. 1, 49-50 (1990).

\section{Acknowledgements}

H. D. thanks for the hospitality and help extended to him by Prof. Dr. J. Alonso and his group in Val ladolid. The authors would like to thank the Direccion General de Investigación - MCT (Grant BQU20000869), the Junta de Castilla y León (Grants VA41/00B and VA017/01), the Fundación Ramón Areces and the Fonds der Chemie for financial support.

[14] GAUSSIAN 98, Revision A.7, M. J. Frisch, G. W. Trucks, H. B. Schlegel, G. E. Scuseria, M. A. Robb, J. R. Cheeseman, V. G. Zakrzewski, J. A. Montgomery, Jr., R. E. Stratmann, J. C. Burant, S. Dapprich, J. M. Millam, A. D. Daniels, K. N. Kudin, M. C. Strain, O. Farkas, J. Tomasi, V. Barone, M. Cossi, R. Cammi, B. Mennucci, C. Pomelli, C. Adamo, S. Clifford, J. Ochterski, G. A. Petersson, P. Y. Ayala, Q. Cui, K. Morokuma, D. K. Malick, A. D. Rabuck, K. Raghavachari, J. B. Foresman, J. Cioslowski, J. V. Ortiz, A. G. Baboul, B. B. Stefanov, G. Liu, A. Liashenko, P. Piskorz, I. Komaromi, R. Gomperts, R. I. Martin, D. J. Fox, T. Keith, M. A. Al-Laham, C. Y. Peng, A. Nanayakkara, C. Gonzalez, M. Challacombe, P. M. W. Gill, B. Johnson, W. Chen, M. W. Wong, J. L. Andres, C. Gonzalez, M. HeadGordon, E. S. Replogle, and J. A. Pople, Gaussian Inc., Pittsburgh PA, 1998.

[15] U. Andresen, H. Dreizler, J. U. Grabow, and W. Stahl, Rev. Sci. Instrum. 61, 3694-3699 (1990).

[16] H. Suzuki, N. Ohishi, N. Kaifu, S. Ishikawa, T. Kasuga, S. Saito, and K. Kawaguchi, Publ. Astron. Soc. Japan 38, 911-917 (1986).

[17] J. C. Pearson, C. A. Gottlieb, D. R. Woodward, and P. Thaddeus, Astron. Astrophys. 198, 13-15 (1988) and citations herein. 